\title{
Just One Bite?
}

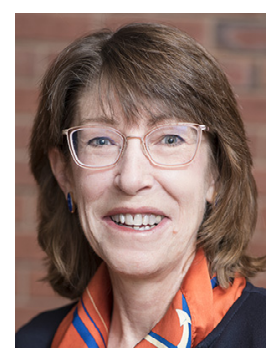

A familiar phrase for both nutritionists and parents who are trying to increase the willingness of young children to try novel food. It is not a new area of study. However, I was intrigued by a study published in JNEB in 2002, ${ }^{1}$ where the number of children willing to try a novel vegetable (kohlrabi) was so high (76\%) in the positive treatment group (storybook reading with positive kohlrabi message) that the results and study were severely limited. The authors had pretested the scenario with a small sample in which less than half were willing to taste the vegetable. Children can surprise you.

A similar result was found in a study across 14 countries $(n=410$, age range 4 to 14 years). ${ }^{2}$ Data were collected before and after a workshop for children called Art on a Plate. Nearly $90 \%$ of the children said they would like to try a spinach and fruit salad at their next meal before the workshop. The workshop involved hands-on experience with the food and interaction with a chef. A particular confounder in this study was self-reported hunger, which decreased after the workshop.

A more complicated study design evaluated the use of child-centered nutrition phrases with repeated exposure on willingness to try and consumption in 87 children aged 3 to 6 years old. ${ }^{3}$ Although children were more willing to try foods at the second vs. the first offering, the child-centered nutrition phrases plus the repeated exposure did not affect their willingness to try in comparison with repeated exposure alone. In addition, higher income of the parents was associated with increased willingness to try new foods.

A qualitative study of 34 children aged 4 to 5 years explored positive and negative food perceptions. ${ }^{4}$ Twenty-one of the 34 had negative emotions about trying a new food, while 13 had a positive anticipation. Those with positive anticipation thought trying the new food would be fun, while those with a negative association did not like the unknown. Appearance played a role in this latter group's negative attitude toward the new food.

In this issue, Maiz et $\mathrm{al}^{5}$ present a study in which 202 children aged 8 to 9 years received either healthy habits promotion through nutrition education activities within 3 workshops or hands-on cooking-related activities within 3 workshops. While both strategies appeared to increase diet quality, decrease in food neophobia was significant only for the hands-on group.

This brief summary is only a sliver of the research that has been published on picky eating. Indeed, there are at least 5 systematic reviews on this topic. I do wonder what the overall impact is on health or whether this behavior is transient as the child begins to become more and more independent. As an adult, I know my willingness to try new things, even foods, depends on a variety of factors that also change. Trying to capture all these possibilities is a challenge to our researchers and practitioners, as well as our parents and caregivers. But, I must say, I think we are being thoughtful, creative, and pragmatic in our approaches.

\section{Karen Chapman-Novakofski $P h D, R D N$ Editor-in-Chief}

\section{REFERENCES}

1. Byrne E, Nitzke S. Preschool children's acceptance of a novel vegetable following exposure to messages in a storybook. J Nutr Educ Behav. 2002;34:211-213.

2. van der Horst $\mathrm{K}$, Mathias KC, Prieto Patron A, Allirot X. Art on a plate: a pilot evaluation of an international initiative designed to promote consumption of fruits and vegetables by children. $J$ Nutr Educ Behav. 2019;51:919-925.e1.

3. Lanigan J, Bailey R, Jackson AMT, Shea V. Child-centered nutrition phrases plus repeated exposure increase preschoolers' consumption of healthful foods, but not liking or willingness to try. J Nutr Educ Behav. 2019;51:519-527.

4. Alsulami HA, Goodell LS. Understanding preschoolers' anticipation of trying a new food and past food experiences. $J$ Nutr Educ Behav. 2021;53:352-358.

5. Maiz E, Urkia-Susin I, Urdaneta E, Allirot X. Child involvement in choosing a recipe, purchasing ingredients, and cooking at school increases willingness to try new foods and reduces food neophobia. J Nutr Educ Behav. 2021;53:279289. 